\title{
Effectiveness of a community-based intervention to improve nutrition in young children in Senegal: a difference in difference analysis
}

\author{
Harold Alderman ${ }^{1, *}$, Biram Ndiaye ${ }^{2}$, Sebastian Linnemayr ${ }^{3}$, Abdoulaye $\mathrm{Ka}^{2}$, \\ Claudia Rokx ${ }^{1}$, Khadidiatou Dieng ${ }^{2}$ and Menno Mulder-Sibanda ${ }^{1}$ \\ ${ }^{1}$ World Bank, Africa Region, 1818 H Street, Washington, DC 20433, USA: ${ }^{2}$ Cellule de Lutte contre la \\ Malnutrition, Dakar, Senegal: ${ }^{3}$ Harvard University School of Public Health, Cambridge, MA, USA
}

Submitted 14 December 2007: Accepted 16 April 2008: First published online 18 June 2008

\begin{abstract}
There are few studies of community growth promotion as a means of addressing malnutrition that are based on longitudinal analysis of large-scale programmes with adequate controls to construct a counterfactual. The current study uses a difference in difference comparison of cohorts to assess the impact on the proportion of underweight children who lived in villages receiving services provided by the Senegal Nutrition Enhancement Project between 2004 and 2006. The project, designed to extend nutrition and growth promotion intervention into rural areas through non-governmental organisation service providers, significantly lowered the risk of a child having a weight more than $2 \mathrm{SD}$ below international norms. The odds ratio of being underweight for children in programme villages after introduction of the intervention was 0.83 (95\% CI $0.686,1.000)$, after controlling for regional trends and village and household characteristics. Most measured aspects of health care and health seeking behaviour improved in the treatment relative to the control.
\end{abstract}

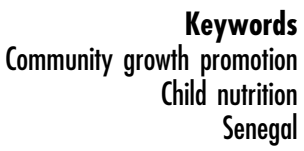

Child nutrition is important both to reduce mortality and to reduce the transmittal of poverty across generations by preventing the impairment of cognitive functions and loss of schooling ${ }^{(1)}$. There is substantial consensus regarding what interventions work to improve child nutrition ${ }^{(2)}$. Many, albeit not all, of these promising interventions lie within the responsibility of the health sector, and target the 'window of opportunity' between pre-pregnancy and 24 months of age. Key interventions that have been proven to be effective in reducing infant mortality, underweight rates and micronutrient deficiencies include the following:

- promotion of exclusive breast-feeding;

- promotion of adequate and timely complementary feeding (at about 6 months of age);

- promotion of key hygiene behaviours (e.g. handwashing with soap);

- micronutrient interventions such as vitamin A and iron supplements for pregnant and lactating women and young children;

- presumptive treatment for malaria for pregnant women in endemic malarial regions and promotion of longlasting insecticide-treated bednets;
- deworming in endemic parasitic areas and oral rehydration in high-diarrhoea regions.

Such evidence on what works, however, begs the question on how to deliver these services at in a full-scale project. Community growth promotion is one widely advocated approach to promoting these recommended practices. Growth promotion has been endorsed in various reports, see for example Allen and Gillespie ${ }^{(3)}$, and in numerous case studies. Similarly, when asked whether they agree with the statement that 'growth monitoring and promotion is ineffective', $63 \cdot 8 \%$ of 529 operational and research professional working in nutrition stated that they disagreed ${ }^{(4)}$. In contrast, published reviews of trials have uncovered little supportive evidence ${ }^{(2,5)}$. This reflects, in part, the fact that there are few studies of community growth promotion in peer-reviewed publications that use longitudinal analysis of large-scale programmes with adequate controls to construct a counterfactual. The current study addresses that gap by reporting on an assessment of the impact of a large-scale community growth promotion programme in Senegal using a difference in difference comparison of cohorts two years after a baseline survey. 


\section{Methods}

\section{Programme and participants}

The Senegal Nutrition Enhancement Project was designed to extend nutrition and growth promotion intervention into rural areas through non-governmental organisation (NGO) service providers under the direction of the Cellule de Lutte contre la Malnutrition (CLM), the multisectoral coordination commission responsible for the implementation of the national nutrition policy. The rural interventions of the programme were targeted to three regions (Fatick, Kaolack and Kolda) with twelve NGO contracted to implement thirty-four district-level subprojects. In collaboration with local government authorities and district health workers, NGO organised communities, which in turn mobilised community health and nutrition workers to provide growth monitoring services and counselling to all mothers of young children in selected communities, encourage pregnant women and caregivers to seek preventive health care such as antenatal and postnatal care and coordinate with health personnel for delivery of essential health services, such as vaccination, deworming and micronutrient supplementation on a biannual basis. The dosage for deworming and vitamin A, respectively, were $500 \mathrm{mg}$ mebendazole every 6 months for children between 12 and 59 months and 100000 IU for children between 6 and 11 months and 200000 IU for children between 12 and 59 months.

Service provision commenced in mid-June 2004 and expanded rapidly. The number of children under 3 years enrolled in community-based growth monitoring and promotion almost doubled from June 2004 (102857) to June 2005 (196088). This represents $15 \%$ of the children in the age cohort; the project expansion initiated in early 2007 aims at covering $40 \%$ of children under 5 years by 2011 .

\section{Procedures}

At the initiation of the project it was determined that the key indicator of nutritional impact would be improvements in the number of underweight children using a cut-off of minus two $Z$ scores for weight for age, in keeping with one of the indicators of the Millennium Development Goal for eradication of extreme poverty and hunger ${ }^{(6)}$. This indicator was also established as the key monitoring indicator to be used to determine funding for the expansion of the programme from coverage of $15 \%$ of the age cohort to $40 \%$. Given that children are most susceptible to malnutrition in the first 3 years of life ${ }^{(7)}$, the evaluation focused on this group, although the project had a wider target group. A power calculation was used to determine the necessary sample to detect a difference of 3 percentage points between any improvements over time in the underweight percentage in the control population and improvements in the intervention group. An acceleration of the rate of improvement in malnutrition of 3 percentage points over the regional trend in 2 years of programme operation would compare favourably with those reported in the literature for full-scale programmes ${ }^{(8)}$. The sample needed to detect this difference in differences was 110 intervention and 110 control clusters, each with twenty observations.

Prior to the initiation of the project in the communities, the NGO provided lists of all villages in which they intended to work. These were then compiled into a single list of approximately 1000 villages and the cumulative population of all the villages included in a column. This figure was then divided by 220 to provide a sampling interval. A random number was then selected and the village with this cumulative population was chosen; the next cluster chosen was that village with the cumulative population equal to the initial random number plus the interval. The subsequent cluster was that with a cumulative population indicator equal to the initial population plus twice the interval and so forth until 220 clusters were selected. In a few cases, a relatively large village had two, or in one case three, clusters chosen. Thus, a total of 211 villages correspond to the 220 clusters.

The villages chosen were then randomly divided into two equal lists, one was a list of villages in which the contracted NGO were to begin community mobilisation as soon as baseline data had been collected in March-May 2004 and the other was a list of villages that were to continue to receive the core services of the health sector but which would not receive community growth promotion via the contracted NGO until after a second round of data collection in March-May 2006. The NGO were, however, free to prioritise the timing of service provision to any other communities not on either of these lists. The services delivered by the NGO to the sampled intervention communities did not differ from those received in the wider set of communities included in the overall programme. Similarly, no additional research staff were assigned to these communities other than those involved in the baseline and resurvey of households.

A census of the households was prepared in each selected community. Twenty households in each cluster were selected at random for the baseline interviews from the subset of households that contained at least one child less than 3 years of age. The interviews collected information on the household's socio-economic status and health-care practices using a questionnaire adapted from the Demographic and Health Survey instrument ${ }^{(9)}$. Weights (using SECA scales, as with the DHS survey) and heights of children under 3 years and information on recent morbidity were also collected at this time. This listing and selection were repeated for the second round. As the analysis is based on household surveys, it compares cohorts of children present in the communities whether or not they participated in any activities organised by the NGO rather than comparing weight gain of individuals 
longitudinally. As we do not know the actual take-up of the services by the households in the villages, the estimates therefore provide an average of the intervention impact and constitute a conservative lower bound for the effectiveness of the intervention on the treated.

While the initial assignment of interventions to communities was in keeping with a cluster-randomised control evaluation, the analytical approach was designed as a difference in difference evaluation, that is, to measure differences in average nutritional status in 2006 compared to 2004. As the project was executed as a full-scale intervention, the NGO that were operating the project had no direct contact with most members of the research team or with the firm, Centre de Recherche pour le Développement Humain, which collected the data. While this enhances the external validity of the results, it also contributed to some departure from the initial design; about $30 \%$ of the villages chosen to receive the programme in the first wave were not prioritised by March 2006. Conversely, eight of the intended control villages were provided the services.

It is necessary that the analysis take this cross-over into consideration. Using the baseline data, we verified that the villages that were in the planned intervention group but that did not actually receive the intervention were slightly better off in terms of baseline nutritional status than the rest of the intervention group. They also had more market infrastructure but less access to NGO and clinics. While we can control for observed baseline conditions, any unobserved characteristics of the communities that are also correlated with treatment after the deviation from the initial design can potentially bias the measured impact of the programme on behaviours and on nutritional status. Thus, it is necessary to control for these in the analysis. We do this by including dummy variables for each village in a multivariate logistic regression of the probability of being underweight. The dummy variables control for any villagelevel fixed effects that enter a regression model linearly, both those that are potentially observable and those that are unobservable. The regressions are based on the observations of children less than 3 years of age in each round. Individual observations from both the 2004 and the 2006 survey rounds are included in a single stacked crosssectional regression.

The regressions also include a dummy variable for the time trend. Given that the average village characteristics are accounted for by the dummy variables, this second-round dummy variable picks up the average time trend for both the intervention and the control sites. An additional dummy variable for the individuals who resided in the villages that actually received the intervention between June 2004 and March 2006 then provides the measure of the treatment effect. That is, in this difference in difference fixed effect regression the coefficient of this intervention dummy variable indicates the difference in the trend in the intervention sites relative to the average trend; it is a measure of the additional improvement averaged over all the intervention villages.

The regressions also include dummy variables for the age of the child in 6-month intervals at the time he or she was weighed as well as the gender of the child and whether the child was a twin. In addition, the education levels of parents and access to sanitation at the household level were included in the regressions.

\section{Results}

Table 1 reports malnutrition rates between waves of cross-sectional surveys and by intervention and control

Table 1 Summary statistics for dependent and explanatory variables by actual treatment

\begin{tabular}{|c|c|c|c|c|c|c|}
\hline & \multicolumn{3}{|c|}{2004} & \multicolumn{3}{|c|}{2006} \\
\hline & Intervention & Control & $P$ value & Intervention & Control & $P$ value \\
\hline Fraction of children with weight-for-age $Z$ score $<-2$ SD & $0 \cdot 333$ & $0 \cdot 286$ & $0 \cdot 020$ & $0 \cdot 290$ & $0 \cdot 276$ & $0 \cdot 367$ \\
\hline Share of women who took iron supplements & $0 \cdot 849$ & $0 \cdot 842$ & 0.709 & 0.916 & $0 \cdot 879$ & 0.003 \\
\hline Share of women who reported taking malaria pills & $0 \cdot 839$ & $0 \cdot 821$ & $0 \cdot 398$ & $0 \cdot 869$ & $0 \cdot 814$ & 0.001 \\
\hline Share of infants who had liquids introduced early & $0 \cdot 775$ & 0.796 & 0.517 & $0 \cdot 497$ & $0 \cdot 705$ & 0.000 \\
\hline Share of children receiving vitamin $A$ in last six months & 0.640 & 0.579 & 0.033 & 0.725 & 0.629 & 0.000 \\
\hline Share of children receiving deworming in last six months & 0.070 & 0.076 & 0.660 & $0 \cdot 292$ & $0 \cdot 146$ & 0.000 \\
\hline Households with bednets & 0.415 & 0.384 & 0.441 & 0.730 & 0.619 & 0.000 \\
\hline Share of children with diarrhoea in last two weeks & $0 \cdot 337$ & 0.332 & 0.833 & $0 \cdot 263$ & $0 \cdot 296$ & 0.064 \\
\hline Oral rehydration (conditional on diarrhoea) & $0 \cdot 183$ & $0 \cdot 120$ & 0.020 & $0 \cdot 256$ & $0 \cdot 143$ & 0.001 \\
\hline Male child & 0.508 & 0.511 & 0.856 & 0.519 & 0.506 & 0.372 \\
\hline Twin & 0.031 & 0.029 & 0.773 & 0.030 & $0 \cdot 019$ & 0.046 \\
\hline Mother primary education & $0 \cdot 144$ & $0 \cdot 143$ & 0.989 & $0 \cdot 165$ & $0 \cdot 178$ & 0.531 \\
\hline Mother secondary education & 0.018 & 0.026 & $0 \cdot 230$ & 0.031 & 0.035 & 0.635 \\
\hline Father primary education & $0 \cdot 113$ & $0 \cdot 128$ & 0.424 & $0 \cdot 125$ & $0 \cdot 138$ & 0.439 \\
\hline Father secondary education & 0.068 & 0.078 & 0.494 & 0.063 & 0.64 & 0.969 \\
\hline Tap water in dwelling & $0 \cdot 371$ & 0.372 & 0.987 & $0 \cdot 206$ & $0 \cdot 221$ & 0.763 \\
\hline Toilet in house & $0 \cdot 105$ & $0 \cdot 136$ & $0 \cdot 233$ & 0.050 & 0.074 & $0 \cdot 161$ \\
\hline No. of observations & 1899 & 2397 & & 2611 & 3533 & \\
\hline
\end{tabular}

$P$ values corrected for cluster sampling. 
Table 2 Logit regression results for the risk of being underweight $(Z$ score $<-2 \mathrm{sD})$

\begin{tabular}{|c|c|c|}
\hline Independent variable & Coefficient & SE \\
\hline Second round (trend) & 0.024 & 0.065 \\
\hline $\begin{array}{l}\text { Intervention status in the second round } \\
\text { (defined as one if in the treatment group) }\end{array}$ & $-0 \cdot 185^{\star \star}$ & 0.095 \\
\hline Age $6-11$ months & $1 \cdot 067^{* \star *}$ & 0.099 \\
\hline Age $12-17$ months & $2 \cdot 140^{\star \star \star}$ & 0.092 \\
\hline Age $18-23$ months & $2 \cdot 152^{\star \star \star}$ & 0.096 \\
\hline Age $24-29$ months & $1 \cdot 895^{\star \star \star}$ & 0.094 \\
\hline Age $30-35$ months & $1 \cdot 373^{\star \star \star}$ & $0 \cdot 104$ \\
\hline Male child & 0.010 & 0.047 \\
\hline Twin & $0.951^{\star * *}$ & $0 \cdot 137$ \\
\hline Mother's highest education is primary & $-0 \cdot 245^{\star \star \star}$ & 0.072 \\
\hline Mother's highest education is secondary or above & $-0 \cdot 101$ & $0 \cdot 158$ \\
\hline Father's highest education is primary & -0.064 & 0.077 \\
\hline Father's highest education is secondary or above & $-0 \cdot 185^{\star}$ & $0 \cdot 107$ \\
\hline Has water tap in house & -0.025 & 0.069 \\
\hline Has toilet in house & -0.008 & 0.096 \\
\hline Adjusted $R^{2}$ & 0.092 & \\
\hline No. of observations & 10378 & \\
\hline
\end{tabular}

The regression controls for fixed community effects by including a dummy variable for each community but one. The $P$ value of the $F$ test for the joint significance of the age dummy variables is 0.000 .

${ }^{\star}$ Statistically significant at the $10 \%$ level, ${ }^{\star \star}$ statistically significant at the $5 \%$ level, ${ }^{\star \star *}$ statistically significant at the $1 \%$ level.

group as well as means of selected health-care behaviours. While this table is presented primarily as a summary of the variables included in the multivariate regression, it is noteworthy that at the time of the baseline, there are few differences between the communities that subsequently received the treatment and the control group. The treatment communities, however, did have a slightly higher rate of malnutrition at the time of the baseline, while the difference is no longer significant at the time of the resurvey.

Table 2 indicates the full multivariate logit regression results for the main variable of interest for this study, underweight (an indicator variable assuming the value 1 for children whose weight for age $Z$ score is lower than $-2 \mathrm{SD}$ from the US reference group). In addition to indicating that the children in the intervention group were less likely to be underweight, the regression shows that the risk of being underweight increases between 6 and 24 months. Primary schooling for women and secondary schooling for men are also associated with decreased probability of being underweight. No overall secular trend in the risk of being underweight was observed.

The coefficient of the treatment variable in Table 2 has a $P$ value of 0.052 . Thus, the $95 \%$ CI for the OR for the probability of being underweight if the child lived in the intervention villages based on this regression and reported in Table 3 includes one (the point estimate is 0.83 and the $95 \%$ CI $0.686,1 \cdot 000)$. There are, however, other changes in communities with NGO motivators that reveal improvements in health seeking behaviour and increased service delivery. As indicated in Table 3, mothers in the intervention villages were more likely to receive iron supplements during pregnancy as well as to receive malaria pills. Children in the intervention villages were more likely to receive vitamin A as well as deworming medicine in the 6 months prior to the survey period than those in the control group. They were less likely to receive fluids other than breast milk in the first three days after birth as well as less likely to have experienced diarrhoea in the last two weeks. Households in the intervention sites were also more likely to have insecticide-treated bednets. While for many of these behaviours, improvements were observed in the overall population, the changes in behaviours were greater in the intervention communities.

\section{Discussion}

Malnutrition remains widespread in Africa and Asia. However, as reductions in malnutrition often require significant behavioural changes on the part of caregivers as well as increased and regular access to services, progress in reducing malnutrition has been modest in many regions including sub-Saharan Africa. The current study shows that large-scale community growth promotion programmes can achieve sufficient changes in behaviour to achieve a reduction in malnutrition as measured by weight for age.

Part of the difficulty in assessing growth promotion is the fact that most programmes are not a single activity but rather a set of activities, as is this one. Thus, this evaluation is of the entire set of activities and not a single component. That is, it indicates that this particular approach to service delivery has the potential to improve community health.

The focus on community growth promotion in this project also differs from some other approaches to growth monitoring, which emphasise only child weighing $^{(10)}$. However, such monitoring is actually a limited and relatively ineffective interpretation of growth promotion. Growth promotion can provide an opportunity to 
Table 3 Odds ratio of behavioural changes for selected health-seeking behaviours

\begin{tabular}{|c|c|c|c|}
\hline Behaviour & & OR & $95 \% \mathrm{Cl}$ \\
\hline \multirow[t]{3}{*}{ Probability of having an underweight child ( $Z$ score $<-2 \mathrm{sD}$ ) } & Intervention & $0 \cdot 828$ & $0.686,1.000$ \\
\hline & Time trend & $1 \cdot 025$ & $0 \cdot 901,1 \cdot 166$ \\
\hline & No. of observations & 10378 & \\
\hline \multirow[t]{3}{*}{ Probability that woman took iron supplements } & Intervention & $1 \cdot 511$ & $1 \cdot 169,1.954$ \\
\hline & Time trend & $1 \cdot 323$ & $1 \cdot 122,1 \cdot 561$ \\
\hline & No. of observations & 10047 & \\
\hline \multirow[t]{3}{*}{ Probability that woman reported taking malaria pills } & Intervention & $1 \cdot 333$ & $1 \cdot 058,1 \cdot 678$ \\
\hline & Time trend & 0.933 & $0.805,1.082$ \\
\hline & No. of observations & 10147 & \\
\hline \multirow[t]{3}{*}{ Probability that infant had liquids introduced early } & Intervention & 0.393 & $0.317,0.486$ \\
\hline & Time trend & 0.499 & $0.430,0.578$ \\
\hline & No. of observations & 10368 & \\
\hline \multirow[t]{3}{*}{ Probability that child received vitamin A supplementation } & Intervention & $1 \cdot 266$ & $1 \cdot 059,1 \cdot 511$ \\
\hline & Time trend & $1 \cdot 228$ & $1 \cdot 093,1 \cdot 380$ \\
\hline & No. of observations & 10378 & \\
\hline \multirow[t]{3}{*}{ Probability that child had diarrhoea in last 2 weeks } & Intervention & $0 \cdot 824$ & $0.689,0.986$ \\
\hline & Time trend & $0 \cdot 873$ & $0.774,0.985$ \\
\hline & No. of observations & 10378 & \\
\hline \multirow[t]{3}{*}{ Probability that child received deworming medicine } & Intervention & $3 \cdot 021$ & $2 \cdot 281,4 \cdot 003$ \\
\hline & Time trend & $2 \cdot 291$ & $1 \cdot 890,2 \cdot 776$ \\
\hline & No. of observations & 10039 & \\
\hline \multirow[t]{3}{*}{ Household had bednet } & Intervention & $1 \cdot 567$ & $1 \cdot 287,1 \cdot 908$ \\
\hline & Time trend & $3 \cdot 419$ & $2 \cdot 999,3 \cdot 899$ \\
\hline & No. of observations & 10347 & \\
\hline \multirow{3}{*}{$\begin{array}{l}\text { Probability that child receive oral rehydration conditional } \\
\text { on diarrhoea being reported }\end{array}$} & Intervention & $1 \cdot 052$ & $0.723,1.531$ \\
\hline & Time trend & $1 \cdot 170$ & $0.884,1.549$ \\
\hline & No. of observations & 7963 & \\
\hline
\end{tabular}

All OR and $\mathrm{Cl}$ based on results of multivariate fixed-effects regressions similar to that reported in Table 2 . The intervention rows report the additional impact of the intervention over the time trend.

impart knowledge on a face-to-face basis - hence the stress on community mobilisation in many programmes. Many growth promotion programmes, such as the one studied here, also facilitate the provision of inoculations, vitamin and mineral supplements, and deworming medicine. Noteworthy, a review of what works in nutrition ${ }^{(2)}$ claimed that the evidence on growth monitoring showed little or no effect, 'without adequate nutrition counselling and referrals' (p. 429). That review also maintained that common components of growth promotion such as breast-feeding promotion and vitamin A supplementation had sufficient evidence for implementation in all countries with high malnutrition. Similarly, that review endorsed the use of insecticide-treated nets and deworming programmes in specific contexts. The current evaluation of the Senegal programme does not challenge the view that monitoring alone is not effective; what is assessed here is a package of service delivery that includes many measures supported in clinical trials.

The results in the present study are in partial contrast to another review of growth monitoring and promotion, which notes that many such programmes fail because measurements are often too imprecise to serve a screening function and that often motivators are not sufficiently trained to provide useful counselling ${ }^{(6)}$. However, the monitoring or screening function is arguably less essential a feature than the community mobilisation; after all, to be effective, many features of community programmes such as advice on exclusive breast-feeding and the use of colostrum must occur before a child is presented for weighing. Similarly, the screening function is not relevant for the motivation of caregivers to bring their child to obtain vitamin A and deworming practices that were observed to increase in the present study. Thus, it may be that the community meetings and mother's groups are as important, or more so, than the weighing per se. While this is not explicitly tested in the current study, it is consistent with the factors contributing to the success of Thailand's community nutrition programme ${ }^{(11)}$.

The results here also contrast with a similar set of services in southern Senegal that was associated with a reduction in mortality but had no parallel reduction in malnutrition $^{(12)}$. However, the improvements reported here were observed in the context of an overall favourable trend in many health seeking behaviours outside the intervention villages. While the regression results show that the intervention communities had a greater overall improvement in most measures, it is unknown whether the rate of improvement was synergistic with overall improved health delivery or whether it might have been similar in a more stagnant environment. Alternatively, the improvements in the neighbouring communities may reflect a spillover from the intervention, either in shared communication or in access to services.

As mentioned, the research was unable to achieve a complete randomised controlled trial, in part, because of the vagaries of a full-scale programme delivery. The difference in difference analysis, however, achieves 
the criteria of a plausibility study in that the analytic approach endeavours to minimise selection bias to control for confounding variables and to rule out chance ${ }^{(13)}$. The inclusion of fixed effects at the community level as well as the comparatively large number of communities in the intervention and control groups assist in meeting these criteria. Moreover, the correspondence of behaviour changes and the objective measure of malnutrition provide a plausible biological explanation for the outcome in terms of the latter.

Also as mentioned, the fixed-effects regression can address the possibility that factors that determined site selection contribute to the explanation of nutritional status. Even if unobserved community-level factors are correlated with site selection, the measured impact will be unbiased if these factors are fixed. In principle, if the site selection was based on the recognition of factors that contribute to programme success rather than contribute to initial levels, the fixed-effects results might be biased. However, the scale of the intervention, again, weighs against a fortuitous cherry picking of a few promising sites.

In some studies, community group promotion has been found to influence only children under the age of 12 months $^{(14)}$. This is plausible since the promotion of exclusive breast-feeding and the introduction of complementary feeding practices is targeted to these younger children. Similarly, to the degree that advising iron supplementation to mothers also affects birth weight ${ }^{(15)}$, the younger age cohort is most likely to register improvements. However, there is no substantial difference in this study for the difference in OR of underweight for children less than 12 months compared to those aged 12-36 months, although such a comparison with this sample has low statistical power. Given that many of the older children in this sample had already stopped with breast-feeding when service delivery was started, it is possible - but not tested - that these benefits come from the increased deworming ${ }^{(16)}$.

Finally, while the main objective of the research was to test the potential for community-based health system that uses growth promotion as a platform to achieve a reduction in the rate of underweight children, in addition to indicating that this is feasible on a wide scale, these results also show a broader potential for community health promotion. Thus, the benefits of the overall intervention exceed those of reduction in underweight alone. For example, vitamin A prophylaxis is widely recognised as a cost-effective means to reduced child mortality $^{(17,18)}$, while promotion of breast-feeding is recognised as a cost-effective means of preventing neonatal mortality ${ }^{(19)}$. Similarly, even in the absence of iron fortification or supplementation, routine malaria prevention and deworming can reduce anaemia ${ }^{(20,21)}$. There is little question that such measures can have a positive impact; if this improvement in the set of indicators can be shown to be collectively cost effective and sustainable, the expansion of the strategy to the rest of the population seems justified.

\section{Acknowledgements}

Funding support: The study was funded through the Cellule de Lutte contre la Malnutrition, Dakar, Senegal, with support from the World Bank's Research committee (RF-PO87558. RESE-BB).

Conflict of interest: All authors indicate that are no conflicts of interest in their participation in this study.

Authors' contributions: B.N., A.K., K.D. and C.R. led the overall design of the study. H.A. and S.L. took the lead in the methodology and analysis as well as drafting the report. M.M.S. assisted with the drafting of the paper.

Acknowledgements: We would like to thank Salif Ndiaye and the Research Centre for Human Development for the support to the study through the data collection.

\section{References}

1. Behrman J, Alderman H \& Hoddinott J (2004) Hunger and malnutrition. In Global Crises, Global Solutions [B Lomborg, editor]. Cambridge: Cambridge University Press.

2. Bhutta ZA, Ahmad T, Black RE et al. (2008) What works. Interventions for maternal and child undernutrition and survival. Lancet 371, 417-440.

3. Allen L \& Gillespie S (2001) What Works? A Review of Efficacy and Effectiveness of Nutrition Interventions. Asian Development Bank, Nutrition and Development Series no. 5. Manila: Asian Development Bank.

4. Berg A, Levinson J \& Moorthy D (2008) Reflections from the front lines. Swimming upstream with Optimism. A survey of the international nutrition community. Paper presented at 35th SCN Meeting in Hanoi, March 3.

5. Roberfroid D, Kolsteren P, Hoerée T \& Maire B (2005) Do growth monitoring and promotion programs answer the performance criteria of a screening program? A critical analysis based on a systematic review. Trop Med Int Health 11, 1121-1133.

6. http://www.un.org/millenniumgoals/

7. Shrimpton R, Victora C, de Onis M, Costa Lima R, Blössner M \& Clugston G (2001) Worldwide timing of growth faltering: implications for nutritional interventions. Pediatrics 107, 75-81.

8. Mason J, Hunt J, Parker D \& Jonsson U (2001) Improving child nutrition in Asia. Food Nutr Bull 22, Suppl. 3, 3-85.

9. DHS Senegal (1992) Enquête Démographique et de Santé au Sénégal (EDS-II) 1992/93, Demographic and Health Surveys, Macro International Inc.

10. Ruel M (1995) Growth monitoring as an educational tool, an integration strategy and a source of information: a review of experience. In Enhancing Child Growth and Nutrition in Developing Countries: Priorities for Action [P Pinstrup-Andersen, D Pelletier and H Alderman, editors]. Ithaca, NY: Cornell University Press.

11. Tontsirin Kraisid \& Pattanee Winichagoon (1999) Community-based programmes: success factors for public nutrition derived from the experience of Thailand. Food Nutr Bull 20, 315-322. 
12. Pinchinat $S$, Enel $C$, Pison G, Duthe G, Lagarde E, Simondon F \& Simondon K (2004) No improvement in weight-for-age of young children in southern Senegal, 1969-1992, despite a drastic reduction in mortality. Evidence from a growth monitoring programme. Int $J$ Epidemiol 33, 1202-1208.

13. Victora C, Habicht J-P \& Bryce J (2004) Evidence-based public health: moving beyond randomized trials. Am J Public Health 94, 400-405.

14. Alderman H (2007) Improving nutrition through community growth promotion: longitudinal study of the nutrition and early child development program in Uganda. World Dev 35, 1376-1389.

15. Christian P, Khatry S, Katz J, Pardhan E, LeClerq S, Shrestha S, Adhikari R, Sommer A \& West K (2003) Effects of alternative maternal micronutrient supplements on low birth weight in rural Nepal: Double blind randomised community trial. Br Med J 326, 571-576.

16. Alderman H, Konde-Lule J, Sebuliba I, Bundy D \& Hall A (2006) Increased weight gain in preschool children due to mass albendazole treatment given during 'Child Health
Days' in Uganda: a cluster randomized controlled trial. Br Med J 333, 122-126.

17. Beaton G, Martorell R \& Aronson K (1993) Effectiveness of Vitamin A Supplementation in the Control of Young Child Morbidity and Mortality in Developing Countries. New York: United Nations.

18. Bryce J, Black R, Walker N, Bhutta Z, Lawn J \& Stekette R (2005) Can the world afford to save the lives of 6 million children each year? Lancet 365, 2193-2200.

19. Darmstadt G, Bhutta Z, Cousens S, Taghreed A, Walker N \& Luc de B (2005) Evidence-based cost-effective interventions: how many newborn babies can we save? Lancet 365, 977-988.

20. Gulani A, Nagpal J, Osmond C \& Sachdev HPS (2007) Effect of administration of intestinal anthelmintic drugs on haemoglobin: systemic review of randomized controlled trials. Br Med J 334, 1095.

21. Dreyfuss ML, Rebecca JS, Shrestha JB, Pradhan EK, Steven CL, Khatry SK, Shrestha SR, Joanne K, Marco A \& Keith PW Jr (2000) Hookworms, malaria and vitamin A deficiency contribute to anemia and iron deficiency among pregnant women in the plains of Nepal. J Nutr 130, 2527-2536. 